\title{
Vascular consequences of operculoinsular corticectomy for refractory epilepsy
}

\author{
Patrice Finet, MD, ${ }^{1}$ Dang Khoa Nguyen, MD, PhD, ${ }^{2}$ and Alain Bouthillier, MD1 \\ Divisions of ${ }^{1}$ Neurosurgery and ${ }^{2}$ Neurology, University of Montreal Medical Center (CHUM), Montreal, Quebec, Canada
}

OBJECT Surgery in the insular region is considered challenging because of its vascular relationships, the proximity of functional structures, and its deep location in the sylvian fissure. The authors report the incidence and consequences of ischemic lesions after operculoinsular corticectomy for refractory epilepsy.

METHODS The authors retrospectively reviewed the data of all patients who underwent an insular resection with or without an opercular resection for refractory epilepsy at their center. All patients underwent postoperative MRI, enabling a radiological analysis of the ischemic lesions as a result of the corticectomies. The resections were classified according to the location and extent of the insular corticectomy and the type of operculectomy. Each patient underwent clinical follow-up.

RESULTS Twenty patients underwent surgery. All patients underwent insular corticectomy with or without an operculectomy. Ischemic lesions were identified in 12 patients (60\%). In these patients, 11 ischemic lesions (55\%) were related to the insular corticectomy, and 1 was related to the associated periinsular resection. The ischemic lesions associated with the insulectomies were typically located in the corona radiata running from the insula to the periventricular region. Nine patients (45\%) developed a postoperative neurological deficit, among whom 6 (67\%) had an insular corticectomy-related ischemic lesion. All reported neurological deficits were transient. Five patients (25\%) had ischemic lesions without neurological deficit.

CONCLUSIONS Operculoinsular corticectomies are associated with ischemic lesions in approximately $60 \%$ of patients. However, given that no patient had a definitive postoperative deficit, these ischemic lesions have few clinical consequences. Therefore, this surgical procedure can be considered reasonably safe for the treatment of refractory epilepsy. http://thejns.org/doi/abs/10.3171/2014.10.JNS141246

KEY WORDS insula surgery; operculoinsular resection; ischemic lesions; refractory epilepsy

$\mathrm{R}$ EIL first described the insular lobe in 1809. It is considered as the fifth lobe and is not visible at the surface of the brain because of its deep anatomical position. The insula only becomes visible when the sylvian fissure is opened, as it is covered by the frontal, parietal, and temporal opercula. The insula is triangular and consists mainly of 3 short and 2 long gyri separated by the central insular sulcus. The insular cortex lies superficial to the extreme capsule, claustrum, external capsule, and putamen. Its vascular supply is principally provided by perforating arteries arising from the $\mathrm{M}_{2}$ segments of the middle cerebral artery (MCA). . $^{3,8,15,36,38,39}$

The function of the insula is not fully characterized, but it appears to be involved in, among other things, somatosensory representation, viscerosensory functions, visceromotor control, autonomic responses, pain processing, and gustatory and auditory responses..$^{3-5,14,15,28,36}$ Insular seizures may go unrecognized since they can mimic temporal, parietal, and frontal lobe seizures. ${ }^{7,20,21,27,29,32,33}$ As the involvement of the insular cortex is being more and more suspected in some epileptic patients, the structure has been increasingly investigated over the past decade using depth electrodes or combined subdural and depth electrodes through craniotomies with direct insular cortex exposition. ${ }^{6,9,21,23,30,37}$

Because of its restricted accessibility, vascular relationships, and the proximity of functional structures, the insular region is considered a challenging region in which to perform surgery. Nevertheless, because of microsurgical technical progress, it is possible to perform resective surgery of the insular region with lower morbidity. ${ }^{2,24,27,35,41-43}$

The aim of our study was to analyze the vascular risk

ABBREVIATIONS ECOG = electrocorticography; EEG = electroencephalography; LLA = lenticulostriate artery; MCA = middle cerebral artery.

SUBMITTED June 4, 2014. ACCEPTED October 16, 2014.

INCLUDE WHEN CITING Published online April 10, 2015; DOI: 10.3171/2014.10.JNS141246.

DISCLOSURE The authors report no conflict of interest concerning the materials or methods used in this study or the findings specified in this paper. 
of epilepsy surgery in the insular area. More specifically, we report here on the incidence and consequences of ischemic lesions after operculoinsular corticectomies for refractory epilepsy.

\section{Methods}

We retrospectively studied all patients at our center who underwent an insular corticectomy with or without an opercular resection for medically refractory epilepsy from 1998 to 2012, inclusively. Cases with tumors or vascular malformations were excluded. All patients had a postoperative follow-up of at least 6 months.

All patients underwent a comprehensive preoperative investigation that included (for most patients) videoelectroencephalography (EEG) monitoring, brain MRI, neuropsychological evaluation, SPECT, PET, magnetoencephalography, and EEG gated functional MRI. The location and extent of the insular and opercular resections were based on this preoperative workup, which was completed with intracranial EEG recordings in most patients.

All patients underwent postoperative MRI within 3 months after surgery, enabling determination of the areas resected and analysis of the ischemic lesions resulting from the corticectomies. Insular resections were classified as anterior, posterior, superior, inferior, or radical. The MRI included coronal T2 and FLAIR sequences. All patients were clinically evaluated during their postopera- tive hospital stay, 2 months after surgery, and twice a year afterward.

The results of the intracranial investigation and seizure control have been published elsewhere..$^{24,37}$

\section{Results}

Twenty consecutive patients (11 females and 9 males; average age 33 years, range $16-51$ years) who underwent surgery at our institution were enrolled. Seventeen patients had complex partial seizures and 3 had simple partial seizures. Preoperative MRI findings were either normal or revealed abnormalities consistent with focal cortical dysplasia. Fifteen patients underwent intracranial electrode placement with extraoperative long-term recordings to better define the location and extent of the subsequent insular and opercular resection. One patient underwent intraoperative electrocorticography $(\mathrm{ECoG})$ and 4 patients underwent neither intracranial extraoperative recording nor ECoG (Table 1). All patients with intracranial electrode placement underwent MRI the day after the procedure to assess the position of each electrode contact. Based on review of postimplantation MR images, there was no ischemic lesion related to subdural or depth electrode positioning.

Two patients underwent a pure insulectomy. The insulectomies were combined with an opercular resection in 13 patients, a frontoorbital resection in 1 patient, a temporal lobectomy in 3 patients, and a frontal lobectomy in 1

TABLE 1. Patient data

\begin{tabular}{|c|c|c|c|c|c|c|c|c|}
\hline Case No. & Age (yrs) & Sex & Seizure Type & LTIER/ECoG & Side & Surgery & Postop Deficit & IL \\
\hline 1 & 35 & $\mathrm{~F}$ & $\mathrm{CP}$ & LTIER & Rt & Insulect + F operculect & + & + \\
\hline 2 & 36 & $\mathrm{~F}$ & SP & & $\mathrm{Rt}$ & Insulect + FPT operculect & + & + \\
\hline 3 & 16 & M & SP & ECoG & $\mathrm{Lt}$ & Insulect + F operculect & + & - \\
\hline 4 & 23 & $\mathrm{~F}$ & $\mathrm{CP}$ & LTIER & $\mathrm{Rt}$ & Insulect + T lobect & + & $t^{*}$ \\
\hline 5 & 36 & M & SP & LTIER & Lt & Insulect & - & - \\
\hline 6 & 26 & $\mathrm{~F}$ & $\mathrm{CP}$ & LTIER & $\mathrm{Rt}$ & Insulect + T lobect & - & - \\
\hline 7 & 35 & $\mathrm{~F}$ & $\mathrm{CP}$ & & $\mathrm{Rt}$ & Insulect + FP operculect & + & + \\
\hline 8 & 38 & $\mathrm{~F}$ & $\mathrm{CP}$ & LTIER & $\mathrm{Lt}$ & Insulect + T operculect & - & + \\
\hline 9 & 43 & M & $\mathrm{CP}$ & LTIER & $\mathrm{Rt}$ & Insulect + F lobect & + & - \\
\hline 10 & 35 & M & $\mathrm{CP}$ & LTIER & $\mathrm{Lt}$ & Insulect & + & + \\
\hline 11 & 51 & M & $\mathrm{CP}$ & LTIER & $\mathrm{Rt}$ & Insulect + T operculect & - & + \\
\hline 12 & 37 & M & $\mathrm{CP}$ & LTIER & $\mathrm{Rt}$ & Insulect + F operculect & - & + \\
\hline 13 & 28 & $\mathrm{~F}$ & $\mathrm{CP}$ & LTIER & $\mathrm{Rt}$ & Insulect + operculect & - & + \\
\hline 14 & 24 & M & $\mathrm{CP}$ & & Rt & Insulect + F operculect & + & + \\
\hline 15 & 47 & M & $\mathrm{CP}$ & & $\mathrm{Lt}$ & Insulect + FP operculect & - & - \\
\hline 16 & 25 & M & $\mathrm{CP}$ & LTIER & $\mathrm{Lt}$ & Insulect + T lobect & - & - \\
\hline 17 & 23 & $\mathrm{~F}$ & $\mathrm{CP}$ & LTIER & $\mathrm{Rt}$ & Insulect + FPT operculect & + & + \\
\hline 18 & 38 & $\mathrm{~F}$ & $\mathrm{CP}$ & LTIER & Lt & Insulect + FT operculect & - & - \\
\hline 19 & 35 & $\mathrm{~F}$ & $\mathrm{CP}$ & LTIER & Rt & Insulect + PT operculect & - & + \\
\hline 20 & 32 & $\mathrm{~F}$ & $\mathrm{CP}$ & LTIER & Rt & Insulect + FP operculect & + & - \\
\hline
\end{tabular}

$\mathrm{CP}=$ complex partial; $\mathrm{F}=$ frontal; $\mathrm{FP}=$ frontoparietal; $\mathrm{FPT}=$ frontoparietotemporal; $\mathrm{FT}=$ frontotemporal; $\mathrm{IL}=$ ischemic lesion; insulect $=$ insulectomy; lobect = lobectomy; LTIER = long-term intracranial EEG recording; operculect = operculectomy; SP = simple partial; $\mathrm{T}=$ temporal; + = present; $-=$ absent.

* Ischemic lesion related to temporal lobectomy. 

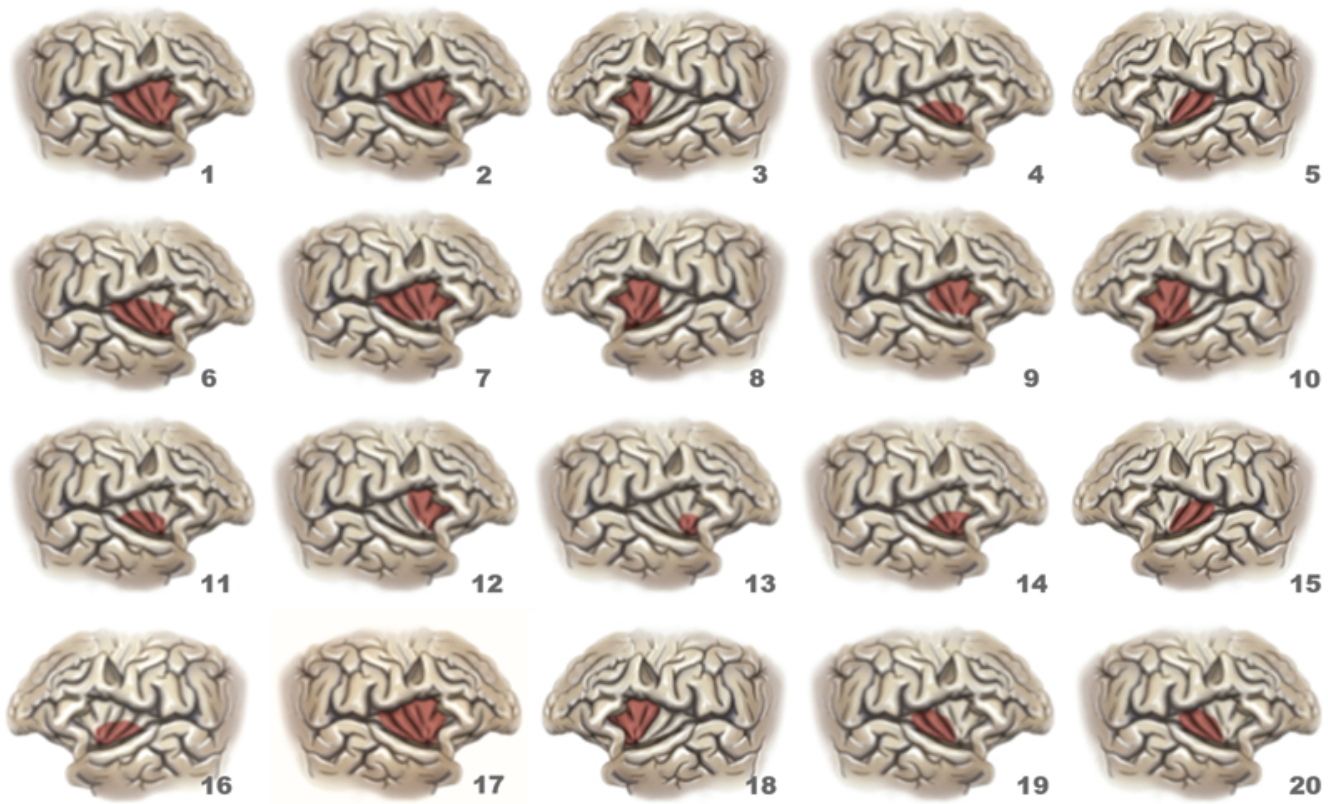

FIG. 1. Illustration showing the localization and the extent of the insular cortex resections in the 20 studied patients. The numbers correspond to the case numbers in Table 1. Copyright Patrice Finet. Published with permission.

patient. The operculectomies were performed as follows: 4 frontal, 3 frontoparietal, 2 frontoparietotemporal, 2 temporal, 1 frontotemporal, and 1 parietotemporal. Two techniques of insulectomy were used, often in combination. For the transsylvian approach, the sylvian fissure was microsurgically opened, with preservation of all $\mathrm{M}_{2}, \mathrm{M}_{3}$, and $\mathrm{M}_{4}$ branches of the MCA. Major veins were preserved most of the time. Neuronavigation could be used when the anatomy of the deep sylvian fissure was difficult to ascertain. A self-retaining retractor was intermittently positioned over the opercula. After the insula was exposed, pial bipolar coagulation between the $\mathrm{M}_{2}$ branches was performed, followed by microscissor opening of the insular surface. Then, the insular cortex was removed by subpial microsuctioning. To achieve complete cortical removal, perforating arteries from the $\mathrm{M}_{2}$ branches were usually sacrificed. For the transopercular approach, cortical incisions were made between the $\mathrm{M}_{4}$ opercular arteries. This was followed by subpial suctioning of the hidden surface of the perisylvian opercula until the periinsular sulcus was reached. After progressively lifting the insular pia, the insular cortex was removed by subpial microsuctioning. Again, most perforating arteries were sacrificed to achieve complete cortex removal. With both approaches, suctioning was never done away from the pia. When performed on the dominant side for language, opercular retraction has to be very delicate and as brief as possible. The exact localization and the extent of resection of the insular cortex were determined precisely for each patient on postoperative MRI (Fig. 1).

All patients underwent MRI between 3 days and 3 months after surgery. These MR images allowed the identification of ischemic lesions in 12 of the 20 studied patients (60\%). Among these 12 patients, 11 ischemic lesions $(55 \%)$ were attributed to the insular corticectomy, while 1 ischemic lesion (5\%) was related to the associated resec- tion (temporal lobectomy). In this latter patient with the ischemic lesion related to the temporal lobectomy, there was no other ischemic lesion.

The insular infarcts were identified mainly on coronal T2 and FLAIR sequences on early MR images (Fig. 2); on T2, FLAIR, and T1 sequences on late MR images (Fig. 3); and/or on diffusion-weighted sequences (Fig. 4) on early MR images. The infarcts were typically located in the corona radiata running from the insula to the periventricular region (Fig. 5). As expected, anterior insular resections were associated with ischemic lesions extending up to the frontal horn of the lateral ventricle, while posterior insular resections were related to ischemic lesions reaching the body or atrium of the lateral ventricle. Inferior and superior insulectomies could present with either an inferior or superior ischemic lesion, respectively. Inferior ischemic lesions typically extended from the insular area, reaching the temporal horn of the lateral ventricle.
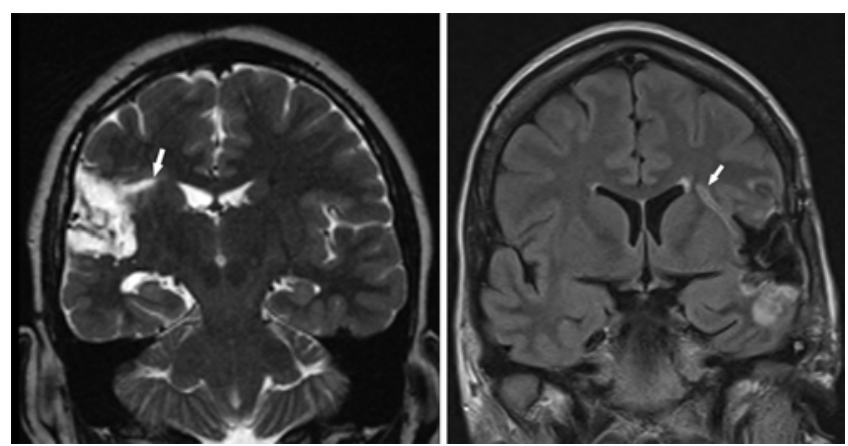

FIG. 2. Early postoperative coronal T2-weighted (left) and FLAIR (right) MR images showing insular resection-related ischemic lesions (arrow) located in the corona radiata running from the insula to the periventricular region. 


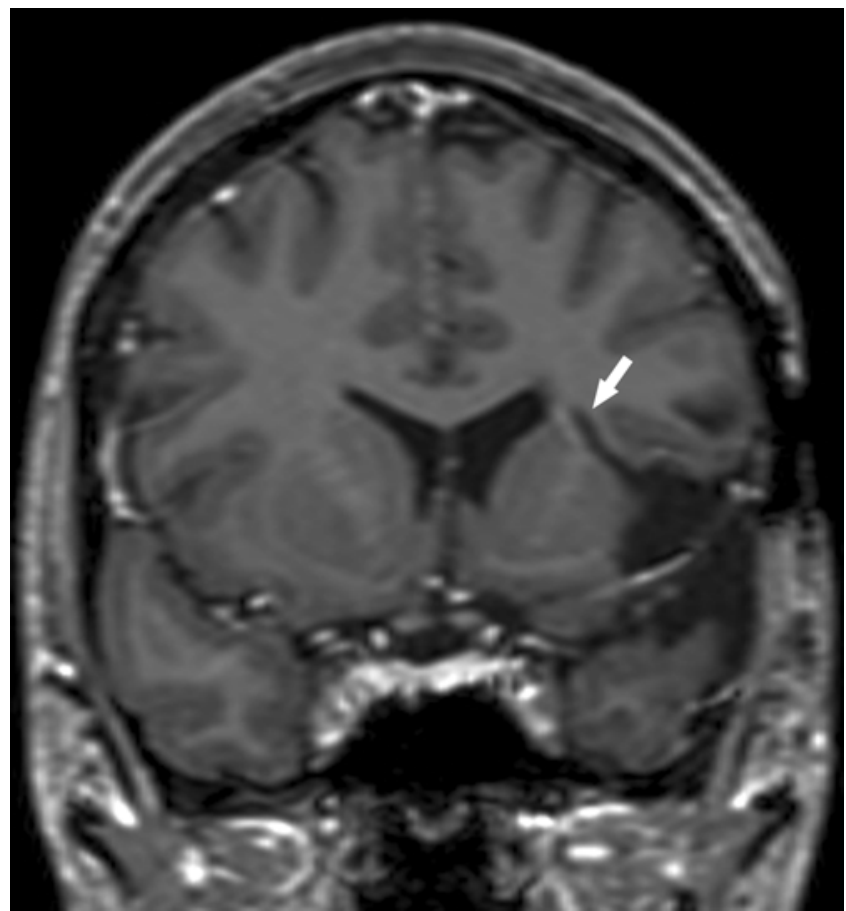

FIG. 3. Late postoperative coronal T1-weighted gadolinium-enhanced MR image revealing an ischemic lesion (arrow) resulting from an insulectomy.

The ischemic lesions were uniformly associated with the different resected insular areas without predilection for a specific region. The risk of developing an ischemic lesion in our series seemed to be the same whether the insular resection was anterior, posterior, inferior, superior, central, or radical. The occurrence of an ischemic lesion was not influenced by whether a cortical dysplasia was identified on MRI.

After surgery, 9 patients (45\%) had neurological deficits. One patient had a left superior homonymous quadrantanopia related to a right posterior temporal ischemic lesion following a temporal lobectomy. The same patient and 6 others had a transient hemiparesis with brachiofacial predominance. One patient had a transient increase in preexisting hemiparesis, 1 patient had a transient dysphasia, and 1 patient had a transient hyperesthesia of the hand. Aside from the quadrantanopia, all postoperative deficits were transient and resolved within 1 week after surgery in most of the patients. Among these 9 symptomatic patients, 6 had an ischemic lesion related to the insular resection. Consequently, 5 patients with an ischemic lesion resulting from an insulectomy were asymptomatic. There was no statistical relationship between the identification of an ischemic lesion and the occurrence of a neurological deficit ( $p=0.4$, Fisher exact test). None of the patients with an ischemic lesion resulting from an insulectomy complained of memory loss. No ischemic lesions were detected in the territory of the lateral lenticulostriate arteries (LLAs).

\section{Discussion}

In this series of operculoinsular corticectomies, $45 \%$ had transient neurological complications (no permanent

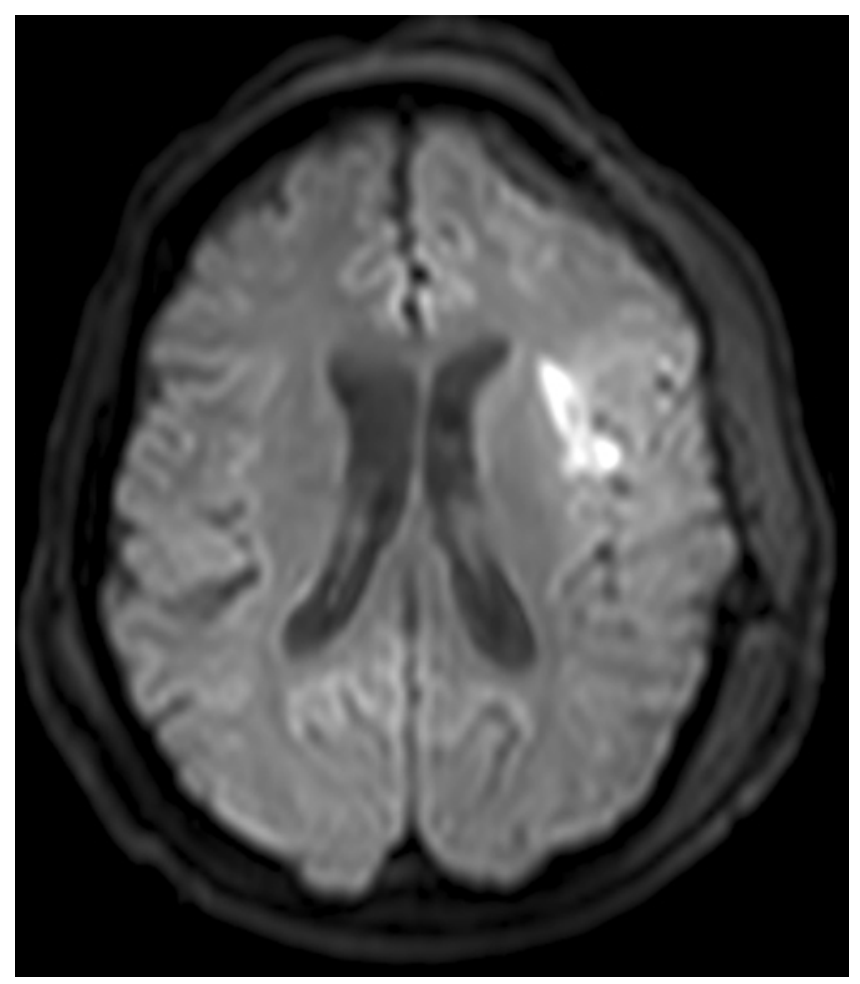

FIG. 4. Early postoperative axial diffusion-weighted MR image showing an acute ischemic lesion related to an insular corticectomy.

deficit) and $60 \%$ had an ischemic lesion on postoperative MRI. Surgery of the insular area is known to be challenging because of its close relationship with vascular structures. $8,15,26,36,38-40$ Immediate postoperative deficits have been previously reported with incidence rates between $9.2 \%$ and $74 \%$ in the literature. Comparison in incidence rate of transient or permanent complications is difficult

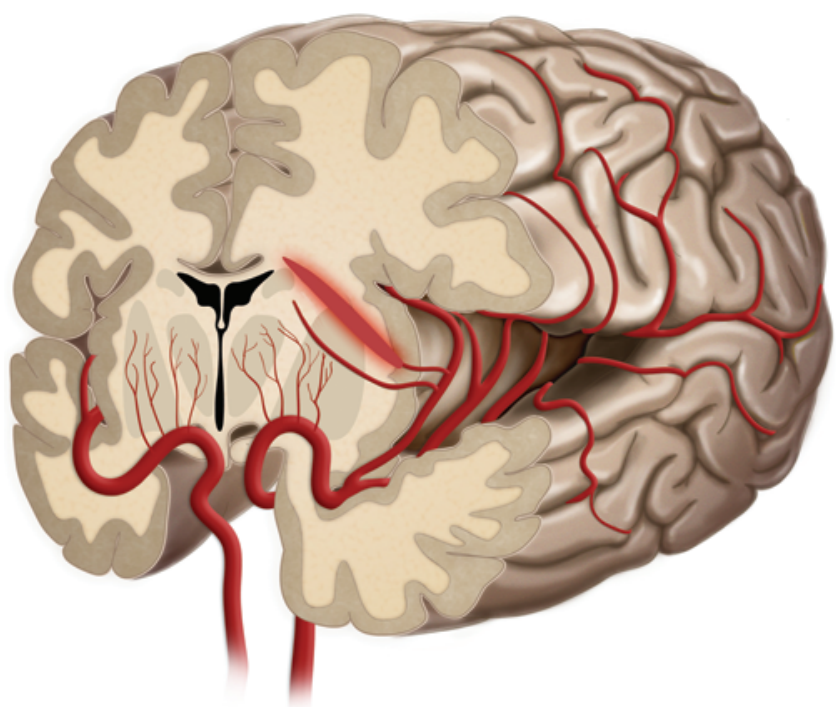

FIG. 5. Drawing illustrating a typical insulectomy-related ischemic lesion located in the corona radiata running from the insula to the periventricular region. Copyright Patrice Finet. Published with permission. 
considering that these series have mostly dealt with patients with tumors or vascular malformations often extending outside the insula both to surrounding lobes and in deeper subcortical structures. In our series, corticectomies were performed in insular cortices without macroscopically visible lesions.

The most important source of permanent deficits identified in previous series for oncological or vascular indications has been vascular damage of the LLAs. ${ }^{12,17,22,35,38,39,44}$ In our series, no ischemic lesion was attributed to an LLA interruption. The ischemic lesions typically encountered after insular corticectomies were linked to injuries of long perforating branches of the $\mathrm{M}_{2}$ segments of the MCA. These branches represent $3 \%-5 \%$ of the perforating branches of the $\mathrm{M}_{2}$ segments of the MCA and reach as far as the corona radiata. ${ }^{39}$ Yaşargil et al. have highlighted that these vessels most commonly arise from the posterior $\mathrm{M}_{2}$ branches. ${ }^{44}$ Coagulation of these long perforating arteries from the $\mathrm{M}_{2}$ segments of the MCA can result in hemiparesis. The remaining perforating branches of the $\mathrm{M}_{2}$ segments are short (85\%-90\%) and medium (10\%) in length and supply the insular cortex, the extreme capsule, the claustrum, and the external capsule. ${ }^{39}$ As the insular cortex and a thin layer of the underlying white matter is removed in insular corticectomies, ischemic lesions related to short and medium branches are not observable. Although perforating branches have been described to arise preferentially from the posterior $\mathrm{M}_{2}$ branches, we did not find a relationship between ischemic lesion occurrence and location of the insular corticectomy in the anterior or posterior insula. We did not observe a zone of predilection for ischemic lesions after insular corticectomy.

Whether these ischemic lesions related to the insular corticectomies are responsible for the transient symptoms presented by our patients remains uncertain. Indeed, only 6 of the 9 symptomatic patients had an ischemic lesion related to the insular corticectomy and 5 patients with a typical insular corticectomy-related ischemic lesion on MRI were asymptomatic. In addition, most of the symptomatic patients recovered within the 1st postoperative week, which would be unusual after an ischemic stroke..$^{16,18,19}$

The transient postoperative deficits can be explained by different alternate hypotheses. Removing the insular cortex itself could be a potential explanation for postoperative deficits because of the disturbance of its intrinsic functions. The rapid functional recovery could then be explained by the relatively small volume of resection and the high connectivity of the insula to compensatory surrounding and distant structures. . $^{1,5,10,11,13,34,35}$

Another possible explanation for the transient postoperative deficits is the occurrence of vasospasm of the $\mathrm{M}_{2}$ branches induced by the surgical dissection along these branches. ${ }^{22,44}$ In our patients, MCA manipulation was minimized by using subpial insular resection. Vasospasm was sometimes observed and was treated with papaverine. One patient had an early postoperative angio-CT scan that revealed the absence of an early postoperative vasospasm.

Opercular retraction is another potential source of postoperative deficits. As demonstrated by Lang et al., a significant retraction of the frontal operculum is required to reach the superior periinsular sulci. ${ }^{22}$ This retraction can be responsible for postoperative hemiparesis or dysphasia when surgery is performed on the dominant hemisphere. Frontal opercular retraction results in direct pressure on Broca's area or compression of the $\mathrm{M}_{3}$ branches of the MCA with frontal ischemia as a consequence. We have not noticed any difference in postoperative deficits between superior or inferior insular corticectomies. Performing an operculectomy on the nondominant side or on the dominant side avoiding Broca's and Wernicke's areas is a method to avoid opercular retraction. ${ }^{12}$ In our series, an operculectomy was carried out only when the opercula were suspected to participate in the epileptic focus. We realized an operculectomy in the majority of our studied patients. Awake surgery is another potential way to reduce deficits linked to opercular retraction. ${ }^{22,25}$

Finally, an early transient postoperative deficit can be due to edema as a result of surgical manipulation, especially since most of the symptoms resolved quickly. ${ }^{31}$

\section{Conclusions}

Ischemic lesions and neurological deficits are not uncommon in operculoinsular corticectomies performed for treating epilepsy but do not result in permanent neurological deficits. Hence, microsurgery of the insular cortex should be considered as a viable option for patients suffering from intractable disabling seizures, provided the surgeon has good knowledge of the perisylvian anatomy and vasculature.

\section{References}

1. Ackermann H, Riecker A: The contribution of the insula to motor aspects of speech production: a review and a hypothesis. Brain Lang 89:320-328, 2004

2. Afif A, Hoffmann D, Minotti L, Benabid AL, Kahane P: Middle short gyrus of the insula implicated in pain processing. Pain 138:546-555, 2008

3. Afif A, Minotti L, Kahane P, Hoffmann D: Anatomofunctional organization of the insular cortex: a study using intracerebral electrical stimulation in epileptic patients. Epilepsia 51:2305-2315, 2010

4. Al-Otaibi F, Wong SW, Shoemaker JK, Parrent AG, Mirsattari SM: The cardioinhibitory responses of the right posterior insular cortex in an epileptic patient. Stereotact Funct Neurosurg 88:390-397, 2010

5. Augustine JR: Circuitry and functional aspects of the insular lobe in primates including humans. Brain Res Brain Res Rev 22:229-244, 1996

6. Bouthillier A, Surbeck W, Weil AG, Tayah T, Nguyen DK: The hybrid operculo-insular electrode: a new electrode for intracranial investigation of perisylvian/insular refractory epilepsy. Neurosurgery 70:1574-1580, 2012

7. Cukiert A, Forster C, Andrioli MS, Frayman L: Insular epilepsy. Similarities to temporal lobe epilepsy. Case report. Arq Neuropsiquiatr 56:126-128, 1998

8. Desai A, Bekelis K, Darcey TM, Roberts DW: Surgical techniques for investigating the role of the insula in epilepsy: a review. Neurosurg Focus 32(3):E6, 2012

9. Desai A, Jobst BC, Thadani VM, Bujarski KA, Gilbert K, Darcey TM, et al: Stereotactic depth electrode investigation of the insula in the evaluation of medically intractable epilepsy. J Neurosurg 114:1176-1186, 2011

10. Dronkers NF: A new brain region for coordinating speech articulation. Nature 384:159-161, 1996

11. Duffau H: A personal consecutive series of surgically treated 
51 cases of insular WHO Grade II glioma: advances and limitations. J Neurosurg 110:696-708, 2009 (Erratum in J Neurosurg 114:1486, 2011)

12. Duffau H, Capelle L, Lopes M, Faillot T, Sichez JP, Fohanno D: The insular lobe: physiopathological and surgical considerations. Neurosurgery 47:801-811, 2000

13. Duffau H, Taillandier L, Gatignol P, Capelle L: The insular lobe and brain plasticity: lessons from tumor surgery. Clin Neurol Neurosurg 108:543-548, 2006

14. Frot M, Mauguière F: Dual representation of pain in the operculo-insular cortex in humans. Brain 126:438-450, 2003

15. Guenot M, Isnard J, Sindou M: Surgical anatomy of the insula. Adv Tech Stand Neurosurg 29:265-288, 2004

16. Hendricks HT, van Limbeek J, Geurts AC, Zwarts MJ: Motor recovery after stroke: a systematic review of the literature. Arch Phys Med Rehabil 83:1629-1637, 2002

17. Hentschel SJ, Lang FF: Surgical resection of intrinsic insular tumors. Neurosurgery 57 (1 Suppl):176-183, 2005

18. Jørgensen HS, Nakayama H, Raaschou HO, Vive-Larsen J, Støier M, Olsen TS: Outcome and time course of recovery in stroke. Part I: Outcome. The Copenhagen Stroke Study. Arch Phys Med Rehabil 76:399-405, 1995

19. Jørgensen HS, Nakayama H, Raaschou HO, Vive-Larsen J, Støier M, Olsen TS: Outcome and time course of recovery in stroke. Part II: Time course of recovery. The Copenhagen Stroke Study. Arch Phys Med Rehabil 76:406-412, 1995

20. Kaido T, Otsuki T, Nakama H, Kaneko Y: Hypermotor seizure arising from insular cortex. Epilepsia 47:1587-1588, 2006

21. Kriegel MF, Roberts DW, Jobst BC: Orbitofrontal and insular epilepsy. J Clin Neurophysiol 29:385-391, 2012

22. Lang FF, Olansen NE, DeMonte F, Gokaslan ZL, Holland EC, Kalhorn C, et al: Surgical resection of intrinsic insular tumors: complication avoidance. J Neurosurg 95:638-650, 2001

23. Levitt MR, Ojemann JG, Kuratani J: Insular epilepsy masquerading as multifocal cortical epilepsy as proven by depth electrode. J Neurosurg Pediatr 5:365-367, 2010

24. Malak R, Bouthillier A, Carmant L, Cossette P, Giard N, Saint-Hilaire JM, et al: Microsurgery of epileptic foci in the insular region. J Neurosurg 110:1153-1163, 2009

25. Meyer FB, Bates LM, Goerss SJ, Friedman JA, Windschitl WL, Duffy JR, et al: Awake craniotomy for aggressive resection of primary gliomas located in eloquent brain. Mayo Clin Proc 76:677-687, 2001

26. Moshel YA, Marcus JD, Parker EC, Kelly PJ: Resection of insular gliomas: the importance of lenticulostriate artery position. J Neurosurg 109:825-834, 2008

27. Nguyen DK, Nguyen DB, Malak R, Bouthillier A: Insular cortex epilepsy: an overview. Can J Neurol Sci 36 (Suppl 2):S58-S62, 2009

28. Nguyen DK, Nguyen DB, Malak R, Leroux JM, Carmant L, Saint-Hilaire JM, et al: Revisiting the role of the insula in refractory partial epilepsy. Epilepsia 50:510-520, 2009

29. Nguyen DK, Surbeck W, Weil AG, Villemure JG, Bouthillier A: [Insular epilepsy: The Montreal experience.] Rev Neurol (Paris) 165:750-754, 2009 (Fr)

30. Park YS, Lee YH, Shim KW, Lee YJ, Kim HD, Lee JS, et al: Insular epilepsy surgery under neuronavigation guidance using depth electrode. Childs Nerv Syst 25:591-597, 2009

31. Potts MB, Chang EF, Young WL, Lawton MT: Transsylviantransinsular approaches to the insula and basal ganglia: operative techniques and results with vascular lesions. Neurosurgery 70:824-834, 2012
32. Ryvlin P: Avoid falling into the depths of the insular trap. Epileptic Disord 8 (Suppl 2):S37-S56, 2006

33. Ryvlin P, Minotti L, Demarquay G, Hirsch E, Arzimanoglou A, Hoffman D, et al: Nocturnal hypermotor seizures, suggesting frontal lobe epilepsy, can originate in the insula. Epilepsia 47:755-765, 2006

34. Sanai N, Polley MY, Berger MS: Insular glioma resection: assessment of patient morbidity, survival, and tumor progression. J Neurosurg 112:1-9, 2010

35. Skrap M, Mondani M, Tomasino B, Weis L, Budai R, Pauletto G, et al: Surgery of insular nonenhancing gliomas: volumetric analysis of tumoral resection, clinical outcome, and survival in a consecutive series of 66 cases. Neurosurgery 70:1081-1094, 2012

36. Stephani C, Fernandez-Baca Vaca G, Maciunas R, Koubeissi M, Lüders HO: Functional neuroanatomy of the insular lobe. Brain Struct Funct 216:137-149, 2011

37. Surbeck W, Bouthillier A, Weil AG, Crevier L, Carmant L, Lortie A, et al: The combination of subdural and depth electrodes for intracranial EEG investigation of suspected insular (perisylvian) epilepsy. Epilepsia 52:458-466, 2011

38. Türe U, Yaşargil DC, Al-Mefty O, Yaşargil MG: Topographic anatomy of the insular region. J Neurosurg 90:720-733, 1999

39. Türe U, Yaşargil MG, Al-Mefty O, Yaşargil DC: Arteries of the insula. J Neurosurg 92:676-687, 2000

40. Varnavas GG, Grand W: The insular cortex: morphological and vascular anatomic characteristics. Neurosurgery 44:127-138, 1999

41. von Lehe M, Wellmer J, Urbach H, Schramm J, Elger CE, Clusmann H: Epilepsy surgery for insular lesions. Rev Neurol (Paris) 165:755-761, 2009

42. von Lehe M, Wellmer J, Urbach H, Schramm J, Elger CE, Clusmann H: Insular lesionectomy for refractory epilepsy: management and outcome. Brain 132:1048-1056, 2009

43. Taillandier L, Duffau H: Epilepsy and insular Grade II gliomas: an interdisciplinary point of view from a retrospective monocentric series of 46 cases. Neurosurg Focus 27(2):E8, 2009

44. Yaşargil MG, von Ammon K, Cavazos E, Doczi T, Reeves JD, Roth P: Tumours of the limbic and paralimbic systems. Acta Neurochir (Wien) 118:40-52, 1992

\section{Author Contributions}

Conception and design: all authors. Acquisition of data: all authors. Analysis and interpretation of data: Finet. Drafting the article: all authors. Critically revising the article: Nguyen, Bouthillier. Reviewed submitted version of manuscript: Finet, Bouthillier. Approved the final version of the manuscript on behalf of all authors: Finet. Study supervision: Bouthillier.

\section{Supplemental Information}

Previous Presentation

Portions of this work were presented as an oral presentation at the Société de Neurochirurgie de la Langue Française (SNCLF) in December 2013.

\section{Correspondence}

Patrice Finet, Division of Neurosurgery, Cliniques Universitaires Saint-Luc, Avenue Hippocrate 10, 1200 Brussels, Belgium. email:patricefinet@hotmail.com. 